WORK IN PROGRESS

\title{
User experience delight from the designer's perspective
}

\author{
Omar Sosa-Tzec
}

Publicado: 31 Octubre 2018

\begin{abstract}
UX designers acknowledge delight as a relevant element of the user experience. This paper investigates how these professionals talk about delight and demonstrates the existence of two viewpoints of delight used in professional practice. The paper introduces a third, unified perspective to serve as the basis of an HCI research agenda that can support UX design practice concerning the notion of delight.
\end{abstract}

Keywords: Delight; User Experience; Pleasure; User Interface Design; Interaction Design; Design Theory.

\section{Introduction}

The vast number of interactive systems and their significant role in people's everyday lives encourages UX designers to create systems that are functional, reliable, usable, and pleasurable [26]. Making a system delightful is an essential need for UX designers since it affects the user's perception and preference towards the system, a fact demonstrated by scholars of marketing, who have argued that delight is a crucial, designed-for element of a product or service. These scholars have demonstrated that delight creates emotional bonds, stronger memories, higher levels of loyalty, user engagement, motivation for re-purchase, and product promotion by word of mouth $[1,6,14]$.

Despite the momentum that the term "delight" has gained among UX designers, I demonstrate in this paper an inconsistency in how UX designers talk about delight. Sometimes, they use delight as a result of appearance and motion, and at other times, UX designers regard delight as a result of efficacy and fulfillment in relation the user's goals and tasks. In this paper, I propose a third perspective, a unified one, as an attempt to remedy this situation and to outline an HCI research agenda on delight that aims to provide UX designers with a theory and framework to discuss and design for delightful interactive systems and user experiences.

This paper comprises three more sections. The next section describes the two viewpoints of delight as discussed by UX designers on the web, sampled mostly from medium.com. Later, I introduce a third perspective which seeks to unify the two viewpoints or themes detected from the thematic analysis and to form the basis for an HCI research agenda to support UX design practice by providing a theory and framework of delight. The last

\footnotetext{
Sosa-Tzec, O.

University of Michigan

Ann Arbor, USA

Email: omarsosa@umich.edu
}

section outlines the activities that would drive this agenda forward.

\section{Two Viewpoints of User Experience Delight Used in the Professional Design Practice}

\subsection{Delight as appearance and motion}

Understanding how motion conveys a message is an essential skill for interaction designers, for which the development of a critical language is necessary. In this regard, Casili proposes that animations associated with interactions must be delightful and meaningful. Such an animation must be pleasurable without detracting from the usability of the interactive system [5]. Gittins relates delight to the user's amusement, surprise, and excitement and regards it as a result of motion features that are intended to make the experience more immersive as well as a result of design features that make the user interface more human or tactile [11]. According to Babich, delight manifests at a surface level, in which a positive first impression draws the attention of the user through very obvious and visceral features. In this regard, Babich defines six elements of what he calls surface experience delight: 1) user interface, 2) microcopy, 3) animation, 4) affordance transitions, 5) sound, and 6) typography [2].

Delight and surprise are two closely related concepts in UX design practice. According to Herrmann, stimulating the user's curiosity is the key to delight and surprise her. Moments of delight and surprise ensure the authenticity of a brand and gives it a competitive advantage [13]. Riddle, Zieba, Caeo and Ellis propose some tactics to design for delight: 1) focus on aesthetics, 2) use feedback to drive conversation, 3) give a gift, and 4) leave little Easter eggs [21]. Gkogka also considers Easter eggs as a way to delight the user [12]. Collins focuses on the delight associated with microinteractions and claims that a delightful UX is in the details hence designers should not overlook them. Nevertheless, Collins allows that not every microinteraction needs to be exciting and include fun transitions and animations. An excess of these features could clutter the interaction rather than making it delightful [7].

\subsection{Delight as fulfillment and efficacy}

Kayan indicates that although delight has become a hot topic in UX design, delight also has become a synonym of cute flourishes and a term to describe design details whose purpose is merely to instill personality and brand into an interactive system. Such details may generate a subtle emotional response in the user but not necessarily a strong feeling of happiness in her [15]. Based on Kayan's self-ethnography, a delightful moment involves one or more of these seven components: 1) something unexpected, 2) 
something that makes the user feel valued, 3) something that makes the user feel smart, 4) something that saves the user's time, 5) something that saves the user a lot of effort, 6) something that makes the world significantly better, and 7) nature. In this sense, a moment of delight occurs when an interactive system helps people be smarter, feel fulfilled, and avoid mundane tasks [15]. Leisio considers delight as a continuum that goes from good to great. A good interactive system is one that gets out the user's way while a great interactive system will introduce something more to the user [16]. In a similar vein, Madhugiri considers a system delightful when it does everything as expected really well while it does something completely unexpected as well [17]. Madhugiri relates delight with efficiency and surprise. A delightful UX is meeting the user's needs before she asks for it. Building a delightful interactive system involves paying attention to details, taking all feedback seriously, and talking to both users and non-users. In this regard, the goal is to build a system that is useful and makes people happy [17].

Maynard claims that a deeper understanding of the user enables the UX designer to find features and mechanisms that provoke delight. Such an understanding supports a creative process that optimizes delight. Creativity thus becomes one crucial part in the UX designer's toolbox regarding delight [19]. Martin considers delight a result of an efficient strategy, the implementation of little things that could cause a big impact [18]. According to Martin, delight is cheap and easy to implement. However, delight is difficult to implement well. To address this, Martin proposes two strategies: 1) to be surprising by making the mundane memorable, and 2) to be personal by knowing the user like a person knows her best friend. Understanding the user's expectations and personality enables the UX designer to identify opportunities to be methodically surprising and personal and therefore to delight her [18].

Shepheard associates delight with ease of use and satisfaction, regarding delight as a result of optimizing for an end goal or a key performance indicator. According to Shepheard, delight materializes through micro-optimizations informed by user research or testing [22]. Obenauer claims that delight for the user is in the details, a result of both function and aesthetic appeal. Function focuses on creating smarter software that removes frustrations instead of creating them, while aesthetic appeal centers on making the interface empathetic and innovative [20]. Slayback argues that delight derives from the personality of the product, not necessarily from usage. According to this UX designer, the product provokes delight in the user when she is surprised by how well the product works concerning something she really wants. Delight is thus a response to 1) the accomplishment of a stated purpose or end, and 2) the excellent execution of such an accomplishment [23].

UX designers from the design agency Thin Martian regard delight as a matter of timing related to the use of animations to add emphasis, importance, and feedback to actions from the user. According to these designers, such an animation is a mechanism for rewarding the user for her actions through a welcoming surprise [25]. Nevertheless, they also affirm that delivering delight is the result of deeply understanding the user's goal, enabling the user to achieve that goal, and letting the user get into a flow. According to these designers, it is the flow what makes the user come back. Moreover, they affirm that reducing anxiety is just as delightful as wowing the user. Designers from Thin Martian consider tailored and personalized interactions an approach to create a delightful user experience [25]. Barkow claims that attempts to provoke delight for the user typically focus on smoothing out frustrations with the product or providing shortterm boosts to the user experience. According to Barkow, the UX designer must investigate deeper frustrations with the product, and only when such frustrations are addressed, can the designer create significant, surprising shortcuts that deliver delight in the longterm [3]. In a similar vein, Crawshaw claims that not all user experiences can be delightful. Crawshaw uses "working on crunching mortgage numbers" and "diagnosing a person with a disease" as two examples to support such a claim. Instead of talking about delighting the user, Crawshaw focuses on the notion of satisfying experiences, experiences that are elegant, fulfilling, and not detracting [8].

Fessenden defines user delight as any positive emotional effect that a user may have when interacting with a device or interface. User delight comprises two types: surface delight and deep delight. In this conception, user interface embellishments can only produce surface delight, while functional, reliable, and usable interfaces can provoke deep delight [10]. Surface delight manifests through animations, tactile transitions or gestural commands, microcopy, beautiful and relevant high-resolution imagery, and sound interactions. On the other hand, deep delight is holistic and derives from meeting all the user's needs, including functionality, reliability, usability, and pleasurability. Deep delight takes place when the user reaches a state of flow as a result of the product working as expected or better by meeting the needs of the user at the right time and place [10]. Fessenden indicates that surface delight is the "sexier" between the two types of delight and that deep delight is harder to achieve. However, when the user experiences deep delight, Fessenden is more prone to recommend the product to a friend and becomes a passionate return user. In this regard, this author relates deep delight to the return on investment of a product. Finally, Fessenden advises UX designers not to force surface delight since it comes with potential branding risks and indicates that prioritizing surface delight over deep delight may convey non-genuineness and deceitfulness [10].

\section{Proposing a Unified Perspective for User Experience Delight}

The characteristics of delight as expressed by these UX designers suggest that delight situates in two opposite viewpoints. One viewpoint regards delight as a result of surprising and amusing design features that heavily rely on the visual, whereas the second viewpoint assigns greater importance to the successful completion of tasks and interactions with the system. Instead of considering one side or the other, I posit a unified perspective to enable the UX designer to think of delight as a broader design-related element of the user experience. This proposed perspective still considers the two viewpoints above. It is rather the emphasis that changes, and as a result, the ways we see and think of delight in interactive systems.

In this perspective, delight is the achievement of a moment of combined arousal, high pleasure, and serendipity. This delight derives from a significant interaction or series of interactions with the system. This delight is embodied through combinations of the visual, the verbal, the aural, the tactile, and the temporal dimensions (modes of interaction with a system).

This unified perspective regards delight as the result of all the communication modes involved in the design of the user interface and its interactions. These modes refer to the visual, verbal, aural, and tactile modes. Furthermore, some systems might include the olfactory mode to account for delight during the user experience. Besides these basic modes, timing is a crucial feature as well. By 
definition, interactive systems have a temporal dimension that must be designed for that is absent in many other media. Thus, this unified perspective comprises five basic dimensions to which a UX designer needs to pay attention when aiming at provoking a delightful user experience: the visual, the verbal, the aural, the tactile, and the temporal.

This definition means that sometimes the UX designer will purposefully seek to create one or several design features that appear novel or surprising to the user but unobtrusive regarding the user's interactions with the system. At other times, the system will be the agent, in its role of the UX designer's deputy [24], that will provoke delight in the user by conveying with clarity how its interface and interaction design features aid and enable the user to accomplish her goals and tasks. In this sense, delight is a matter related to the semiotics [24] and the rhetoric of interactive systems [4].

Finally, this unified perspective urges the UX designer to keep in mind that engagement is a critical aspect to provoke delight in any user experience. The user must be engaged in order to experience delight. The useful application of the five dimensions used to design interfaces and interactions will take place only if the user is present (engaged, concentrated) while she interacts with the system. One interpretation of this idea is that delight occurs when the user enters a state of flow [9] and ongoing semiosis [24] until these processes are interrupted by the recognition of an interface or interaction design feature that reveals to the user the positive, pleasurable development of her interactions with the system.

Such development requires that the user see value in the system and its design, and recognizes the potential of a desirable outcome regarding her goals and tasks as she interacts with the system. If the user sees no value and no potential, it is likely that she interacts indifferently, absent, or disengaged with the system, and therefore, no designer effort could be sufficient to provoke delight in her. The UX designer can always aim to provoke delight in the user. It is also possible that the system's interface and interaction design features lead the user to feel delighted independently of the designer's intent. However, the current conditions of the experience will always affect the user's predisposition to enter a state of flow and engage in a continuous semiosis.

\section{Future work}

The next steps in this exploration of delight include the validation of the introduced unified perspective of delight. Empirical work will be necessary for such validation. The type of work considered for future stages of this research agenda includes semi-structured interviews with UX designers, the application of semantic differentials, and online questionnaires. One activity in this HCI research agenda is to review and synthesize accounts of delight in other non-HCI disciplines, including architecture, philosophy, marketing, and performative arts.

The ideal outcome of this HCI research agenda is the development of a series of guidelines that aid UX designers in designing for delight. The purpose of these guidelines would be to provide UX designers with an orientation toward combining the five dimensions to help the user achieve a state of flow and continuous semiosis. This orientation would also aid UX designers in avoiding design features that interrupt these processes, creating features never to interrupt the user's interaction flow but to anchor the user to the present and thus cause engagement.

\section{Acknowledgments}

I thank Ian Wood for comments that greatly improved this paper.

\section{References}

[1] M. Wayne Alexander. 2010. Customer Delight: A Review. Academy of Marketing Studies Journal; Arden 14, 1: 39-53.

[2] Nick Babich. 2016. Take UX to the Next Level by Adding Delight. Nick Babich. Retrieved May 17, 2017 from https://medium.com/@ 101/stop-pushing-features-and-startdelight-users-ef639194c199

[3] Tim Barkow. 2016. Delivering Delight. Tim Barkow. Retrieved May 17, 2017 from https://medium.com/@tbarkow/delivering-delight8 b837be4ac95

[4] Ian Bogost. 2010. Persuasive games: the expressive power of videogames. MIT Press, Cambridge, Mass.

[5] Davide "Folleto" Casali. 2013. Delightful and meaningful animations are interaction design. Intense Minimalism. Retrieved December 4, 2016 from http://intenseminimalism.com/2013/delightful-andmeaningful-animations-are-interaction-design/

[6] Ravindra Chitturi, Rajagopal Raghunathan, and Vijay Mahajan. 2008. Delight by Design: The Role of Hedonic versus Utilitarian Benefits. Journal of Marketing 72, 3: 4863.

[7] Kaycee A. Collins. 2016. The Delight of Microinteractions. Kaycee A. Collins. Retrieved May 17, 2017 from https://medium.com/@ KayceeAcollins/the-delight-ofmicrointeractions-4b8eccc84b17

[8] Ceara Crawshaw. 2017. Delight is great, but satisfying might be a whole lot more valuable. Medium. Retrieved May 17, 2017 from https://medium.com/@CearaCrawshaw/delight-isgreat-but-satisfying-might-be-a-whole-lot-more-valuable$57 \mathrm{cf} 4 \mathrm{fd} 18 \mathrm{~cd} 6$

[9] Mihaly Csikszentmihalyi. 2009. Flow: The psychology of optimal experience. Harper [and] Row, New York.

[10] Therese Fessenden. 2017. A Theory of User Delight: Why Usability Is the Foundation for Delightful Experiences. Nielsen Norman Group. Retrieved May 17, 2017 from https://www.nngroup.com/articles/theory-user-delight/

[11] Martin Gittins. 2013. Take UX to the next level by adding 'delight.' Webdesigner Depot. Retrieved December 4, 2016 from http://www.webdesignerdepot.com/2013/12/take-ux-tothe-next-level-by-adding-delight/

[12] Eleana Gkogka. 2017. Easter eggs, little delights in UX design. Muzli -Design Inspiration. Retrieved May 17, 2017 from https://medium.muz.li/easter-eggs-little-delights-in-uxdesign-fa26911cd8a3

[13] Athena Herrmann. 2016. The Importance Of Surprise \& Delight In UX Design. Akendi UX Reflections. Retrieved December 4, 2016 from http://akendi.com/blog/theimportance-of-surprise-delight-in-ux-design/

[14] Jack Shih-Chieh Hsu, Tung-Ching Lin, Tzu-Wei Fu, and YuWen Hung. 2015. The effect of unexpected features on app users' continuance intention. Electronic Commerce Research and Applications 14, 6: 418-430. https://doi.org/10.1016/j.elerap.2015.06.003 
[15] Shipra Kayan. 2015. Delight is not cute flourishes. uxdesign.cc. Retrieved May 17, 2017 from https://uxdesign.cc/delight-is-not-cute-flourishes2a1ce118ced5

[16] Tim Leisio. 2016. Good Software Gets Out Of Your Way. Great Software Is An Experience. Medium. Retrieved May 17, 2017 from https://medium.com/@timleisio/goodsoftware-gets-out-of-your-way-great-software-is-anexperience-6b7649f5c3c2\#.c57li3tnb

[17] Mukund Madhugiri. 2016. Build for Happiness vs Usefulness. Build for Delight. Medium. Retrieved May 17, 2017 from https://medium.com/innovation-and-agility/buildfor-happiness-vs-usefulness-build-for-delight-a9488cf921cb

[18] Drew Martin. 2016. 2 Secrets to Designing for Delight. Drew Martin. Retrieved May 17, 2017 from https://medium.com/@DrewMartin/2-secrets-to-designingfor-delight-e08ab7c59699

[19] Rachel Maynard. 2015. Optimizing Delight. Rachel Maynard. Retrieved May 17, 2017 from https://medium.com/@Rachinabox/optimizing-delight$301 \mathrm{a} 64728924$

[20] Alexander Obenauer. 2016. How To Delight Your Users. The New Industrialist by Mindsense. Retrieved May 17, 2017 from https://medium.com/newindustrialist/delightyour-users-10031163b3fe
[21] Ryan Thomas Riddle, Kamil Zieba, Jerry Cao, and Matt Ellis. 2015. Demystifying Delightful Interaction Design. Studio by UXPin. Retrieved December 4, 2016 from https://www.uxpin.com/studio/ebooks/demystifyingdelightful-interaction-design/

[22] Amy Isobel Shepheard. 2016. What is UX and why does it matter? Amy Isobel. Retrieved May 17, 2017 from https://medium.com/@amyisobel/https-medium-comamyisobel-what-is-ux-and-why-does-it-matter-4c4e99720eeb

[23] Zak Slayback. 2016. On Delightful Products \& Going for Gratitude, Not Simply Delight. The Mission. Retrieved May 17, 2017 from https://themission.co/on-delightful-productsgoing-for-gratitude-not-simply-delight-e97890d52f35

[24] Clarisse Sieckenius de Souza. 2005. The semiotic engineering of human-computer interaction. MIT Press, Cambridge, Mass.

[25] Thin Martian. 2016. Delighting Users — Adding magic to everyday interactions. Medium. Retrieved May 17, 2017 from https://medium.com/@ thin.martian/delighting-usersadding-magic-to-everyday-interactions-178d25c9a45a

[26] Aarron Walter. 2011. Designing for emotion. A Book Apart, New York, N.Y. 